\section{First Conference of the British Occupational Hygiene Society}

The first conference of the British Occupational Hygiene Society was held at the London School of Hygiene and Tropical Medicine on November 2, 1953. The Dean of the School, Dr. A. TopPING, welcomed the Minister of Labour and National Service, the RT. Hon. SiR WAlter Monckton, who said :

As the Minister whose department is responsible for administering and developing the laws for securing the health, safety, and welfare of more than 7 million workers in factories and other premises subject to the provisions of the Factories Acts, I am happy to help in the inauguration of a society which brings together scientists and others who have duties and who possess expert knowledge in this particular field of work. The prominence now being given in Government and other quarters to the development of provision for occupational health in its widest sense shows that occupational hygiene is a subject which will receive increasing attention. Occupational hygiene is positive, not concerned only in preventing recognizable diseases: its business is in maintaining full bodily efficiency, well-being, and safety. It is particularly opportune that the foundation of this Society should come at a time when efforts are being made to establish and develop this important service to industry.

Your members, in their various capacities, will be able to give much corrective advice on many of the problems which will arise. You will know that my Ministry is particularly concerned with human relations in industry. Industrial progress is dependent more than anything else on the human element in industry-on the health, well-being, and good will of managements and their workers. The application of knowledge of practice of many kinds is necessary to attain these objects. The medical profession, the physiologist, and the psychologist must work hand in hand with the engineer, the chemist, and the physicist, and a vital factor must be the closest collaboration between industrial research and industrial health research. Occupational hygiene involves study of the reactions of man to his environment. The physician, the medical scientist, and the psychologist study man : the physical scientist (and he includes the engineer) is concerned with man's environment. It is by the harnessing of these different elements that I look for enduring achievements by your Society.

Industrial hygiene has always been a matter of first importance in the work of my Factory Inspectorate. Quite apart from special requirements in Regulations dealing with those industries and processes where specific types of occupational disease and poisoning are likely to occur, the Factories Act aims at preventing the ordinary ailments, and not merely those which are unquestionably industrial in character and origin. It is not without significance that the opening sections of that Act relate to matters of hygiene, to provisions about cleanliness, overcrowding, ventilation and temperature, lighting, and so forth, and that a later part of the enactment deals with washing facilities, cloakroom accommodation, protective clothing-all within the subject dealt with by your Society.

It will be generally agreed that the number of chills and colds avoided, or indeed the amount of positive health resulting from such provisions, whilst not capable of such statistical statement, must be very considerable indeed. In the incidence rates of cases of notifiable occupational diseases a broad picture of progress and the effect of applying the principles of occupational hygiene can be obtained. Take, for example, the case of lead poisoning. In 1900 there were 1,050 cases of lead poisoning in industry in this country, of which 38 ended fatally, whilst in 1952 there were only 48 cases, none of them fatal, with a greater number of employed persons at risk. At present notifiable industrial diseases scheduled under the Factories Act are classified under 14 different headings, and the total number of cases in all these classes was 594 not much more than half of the number of lead poisoning cases at the beginning of the century. The small numbers now appearing in the tables of industrial poisoning cases published each year in the Report of the Chief Inspector of Factories indicate to what extent precautionary measures which constitute the practice of occupational hygiene have been successful in the past. But these results must not be regarded as an excuse for complacency, and much work lies ahead.

During the last decade there has been a marked increase in the interest shown in health matters by industry, but it cannot be said that the facilities for studying occupational risks to health have kept pace with the growing awareness of the importance of this subject. The establishment of your Society should provide a means of arousing a greater interest in occupational hygiene by focusing attention not only on the medical aspects of its practical application, but also on the engineering, chemical, and physical nature of many of its problems. If progress is to be obtained in industrial health, everyone in industry has some contribution to make, and joint and sustained effort is required. It was with this object in view that Ernest Bevin, in 1943 when he was Minister of Labour and National Service, called together a conference on industrial health, which was addressed by experts from the broad and varied fields concerned. As a result of this, advisory panels were set up to advise the Factory Department on dust hazards, dermatitis, ophthalmology, radiology. The members of these panels came from industry, medicine, science, and Government departments, and as Minister I am indebted to the work which they have done.

One of the pressing demands in industry at the present time is the need for people, suitably qualified to apply principles of health and safety, which are closely interwoven and closely concern the welfare of the industrial worker in his factory environment. Occupational hygiene is thus one of the subjects which should be introduced into the essential training and education of all concerned with these matters, in order that the doctor, engineer, scientist, or personnel officer may recognize 
occupational hazards and realize that each has a contribution to make towards the preventive methods which ought to be adopted. This applies equally in the field of research. Whilst the primary aim of most industrial research is quite understandably concerned with discovering new and improved methods of production, it is important that principles of hygiene should be fully understood and practised by research workers, so that the safest and healthiest methods and designs may be incorporated into new plant at the pilot stage. Joint consultation between those carrying out industrial research and those responsible for occupational health is essential before any new project is put into production.

It is self evident to those who study human problems that using our man power to the best advantage means a great deal more than just seeing that the right man is in the right job, important though that is. Above everything else, it means understanding men and women, understanding things that influence their attitude to their daily work and to one another. We want to know a great deal more than we do at present about the things that release the full measure of human resource and enterprise, about the relationship between incentive and environment, and the extent to which environment can enhance the effectiveness of the group-in short about those human factors which will be the particular study and concern of your Society. The field of your enterprise is very large indeed, and I am sure that you will have much to contribute to our present knowledge of the things that make for greater satisfaction and, consequently, greater happiness.

I have a special pleasure in being here today in that I can personally congratulate you on the choice of your first president, Dr. Bedford. He has long been known as an international authority in special fields of environmental hygiene. For many years he has advised the Factory Department of my Ministry, and many of my inspectors have had cause to remember his teaching in the sciences of heating and ventilation. Members of the House of Commons have a particular reason to be grateful to him. His work in balancing the heating and ventilating system in the House can only be appreciated by those who had previously to endure blasts of hot and cold air from all sections of the House with bewildering frequency.

Although this Society of yours with its special aims and objects is new to this country, there is a well known body in the United States, and I am sure that we are all delighted that the American Association is represented here today by Dr. Henry F. Smyth Jr. As is our custom, we accept innovations with caution until the need is evident. The founders of this Society have followed this principle and have given much thought to its constitution and to the qualifications for membership. Membership is not limited to scientists, as you know, but may include others with interests and responsibilities in the wide field of occupational health. In this way, scientists and industrial doctors and others may contribute their gifts and knowledge to the common purpose. In my Ministry, we have, in the Factory Department, direct experience of this sort of team-work between the various professions concerned, and I am convinced that it is the right way of working.

In the Ministry of Labour we shall watch your progress with lively interest and I wish you every success in the important tasks that lie ahead.

\section{Occupational Hygiene in Great Britain \\ THOMAS BEDFORD}

It is no new discovery that health is affected by occupation, nor is it only in recent times that occupational hygiene has been practised.

The writer of Ecclesiasticus described the work of various craftsmen. He wrote :

"The smith also sitting by the anvil, and considering the ironwork, the vapour of the fire wasteth his flesh, and he fighteth with the heat of the furnace: the noise of the anvil is ever in his ears, and his eyes look still upon the pattern of thing that he maketh : he setteth his mind to finish his work, and watcheth to polish it perfectly."

He also gave a graphic description of the work of the potter. These passages reveal a clear realization of the stresses imposed by occupation.

Again, four centuries before the Christian era, Hippocrates alluded to the difficult breathing of the metal digger.

In the sixteenth century Agricola referred to the perilous nature of mining because of the dust which caused asthma, and at times produced consumption. On that account, in the Carpathian mountains there were women who had married seven husbands, all of whom miner's consumption had brought to an early grave.

Perhaps the first reference to the application of preventive measures in industry goes back to Roman times, when Pliny mentioned that men refining cinnabar enveloped their faces with loose bladders so that they could see without inhaling the fatal dust.

Development in Great Britain.-The history of the application of industrial hygiene in this country in more modern times is largely reflected in the industrial legislation of the past 150 years.

The introduction of power-driven machinery in the latter part of the eighteenth century made it possible for a child to perform tasks which had previously required the strength of an adult. This encouraged the exploitation of child labour, particularly in the textile mills of the north. Very young children, especially those indentured under the Poor Law, were required to work long hours, and often at night, in unhealthy surroundings. Following an outbreak of fever in the cotton mills around Manchester towards the close of the eighteenth century, there was agitation for the regulation of the working 